\title{
Sophie Germain's Early Contribution to the Elasticity Theory
}

Marie-Sophie Germain (1776-1831) was born in Paris to a family of the (increasingly) rich bourgeoisie. She blossomed, in her teens, into a self-taught mathematician. Her contributions to number theory, solutions to special cases of the Fermat theorem, are still remembered and referenced, along with a rich harvest of anecdotes. Her contribution to the development of the theory of elasticity is less known, though we owe her the first mathematical treatment of the resonance nodes of vibrating membranes.

Germain, by her own account, selected the study of mathematics to isolate herself from mounting social unrest and political revolution. Her father had been elected as a representative of the bourgeoisie-le tiers état-to the congress of Versailles. It was the prohibition of the meetings of this assembly that sparked the events of July 14, 1789-the French Revolution. Reportedly, when Germain read an account, in her father's library, of Archimedes who was slaughtered by a Roman soldier during the siege of Siracusa because he was too engrossed in a mathematical problem to notice the events, the young teenager singled out mathematics as a subject absorbing enough to distract one's mind from the unsettling events at hand.

Unfortunately, the study of mathematics was inappropriate for a merchant's daughter. Germain's parents tried to curb her worrisome activities by preventing her studies in every way. When she resorted to study at night, they hid her clothes, forbade a fire, and hid away candles. It is said that Germain would rise to study mathematics in the dead of night, wrapped in bedcovers, while it was so cold that the ink would freeze in the inkpot. Her family soon desisted. Although no institutions of higher education would admit women as students, those were times when the laws of society, and the role of women therein, were being rewritten. While Germain studied Gauss's Disquisitiones Arithmeticae, Paris grew with political chat-rooms, the salons, hosted by women. In 1789, Paris also witnessed the 12 -mile march by 6,000 women on the royal palace of Versailles. This Amazon army, led by the Belgian Théroigne de Mericourt, once a courtesan, was instrumental in bringing Louis XVI to Paris under direct control of the French citizens.

Although women had no possibility of receiving a formal education, the Ecole Polytechnique, newly founded to consolidate the new role of France in positivist

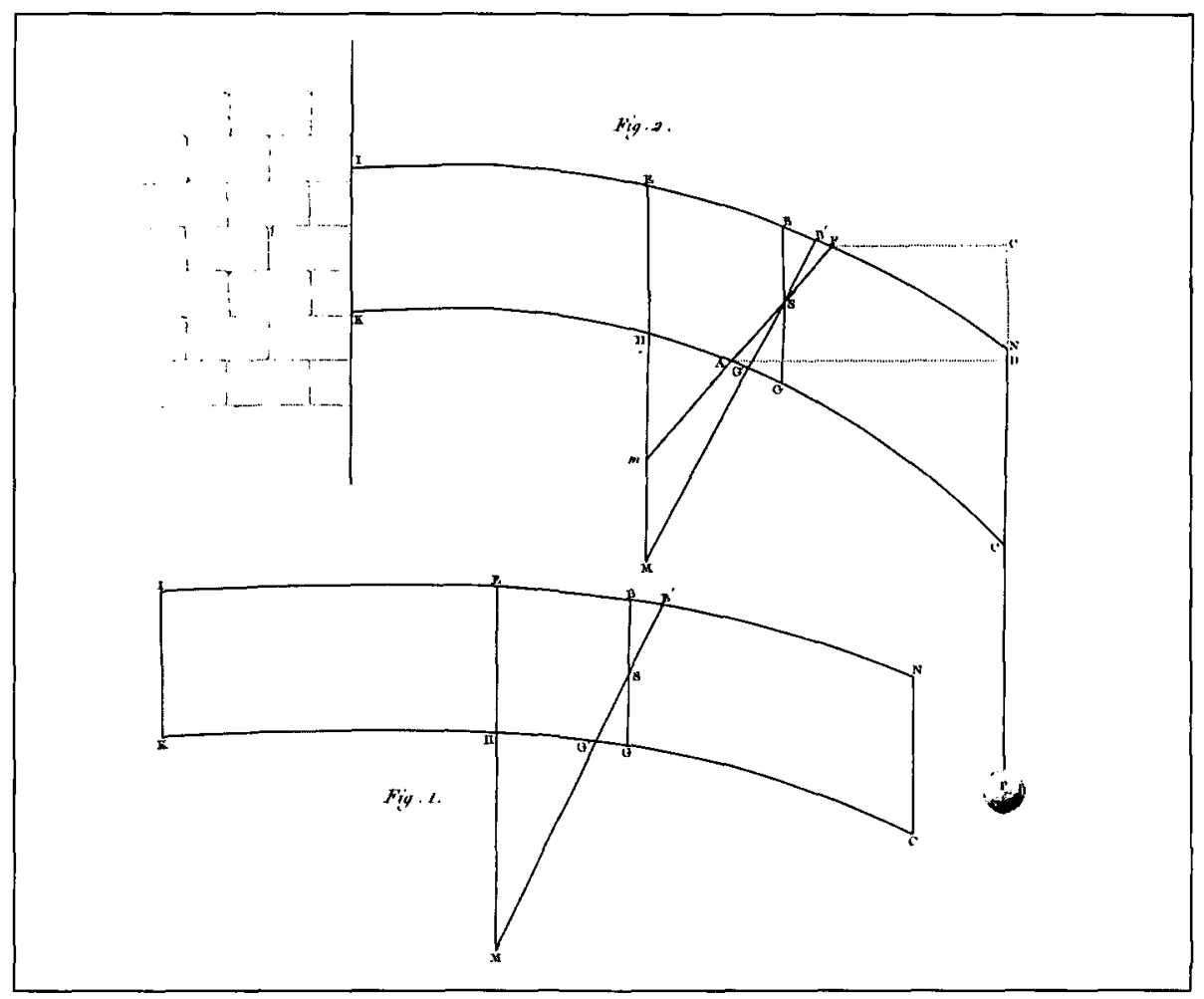

Sophie Germain's sketch of an elastic bar and its radius of curvature when bent by an external force, taken from her book on the theory of elastic surfaces (1821).

Europe, produced written notes for students, and requested that solutions be submitted to the problems. Germain obtained these notes under the name of Monsieur LeBlanc. She revealed herself as a woman when Lagrange desired to meet the student who submitted such brilliant solutions. Under the same name of LeBlanc she initiated a correspondence with Gauss, offering solutions to some of the problems of his Disquisitiones Arithmeticae, and asking for advice on how to proceed with her studies. Gauss was pleased with his correspondent from Paris, who was able to offer a partial proof of Fermat's theorem. In 1806 Napoleonic troops invaded Brunswick where Gauss resided. Germain recommended his safety to General Pernety, a friend of the family, and it is he who revealed to Gauss the true identity of his Paris correspondent.

The appreciation for her work allowed Germain to be invited to attend the demonstration which set the basis for interest in vibrating surfaces. The acoustician Chladni demonstrated in 1808 at the French Academy of Sciences the vibrating modes of plates with grains of sand, which distributed themselves in fixed patterns on membranes made to resonate with the arch of a violin. This experiment duly impressed Napoleon, who approved a public contest for the theoretical description of these patterns, with a prize of 3,000 francs. The beginnings of the modern theory of elasticity did not thus spring from interest in practical engineering problems, but from a desire of finding, with the new mathematical tools at hand (the variational methods of Lagrange), a solution to physics problems. The call, open for two years, received only one entry, by Sophie Germain.

This entry contained a basic hypothesis, namely, that the elasticity was proportional to the sum of the inverses of the principal radii of curvature of a surface. Unfortunately, no proof was offered for the hypothesis and the derivation of the subsequently inferred equations was not correct, so the prize was not awarded, but the contest was extended. Lagrange, who was a member of the commission that judged the entry to the contest, offered the correct partial differential equation. However, he died two years later and Germain remained unable to derive Lagrange's equation by 
variational calculus. Her ability resided mostly in algebraic manipulations, and she tried to generalize the work of Euler on the elasticity of bars, extending it to two dimensions. Germain related elasticity to the sum of the principal curvatures of a surface.

The objective of the contest was to offer a mathematical explanation of Chladni's experiment, and Germain successfully experimented with laminae. In her second entry (again, the only one) to the extended contest, she modified her equation and proved that it was correct in a number of special cases. The experimental part earned her an honorable mention from the jury, and led her to publish her work-at author's cost-in 1821. Another stimulus to publication was the fact that Poisson was devoting his attention to the problem of elasticity, offering another approach and yet another equation, and consistently avoided to duly acknowledge Germain's preceding and ongoing work. Partly to patch up this breach of confidentiality, the contest was called again, with a gold medal as a prize. The gold medal was awarded to Germain, but, to the annoyance of those attending the public ceremony, she decided not to appear in public.

In 1828, a new approach was given to the solution of the plate equation: an equation by Fourier, in the form of series of sines and cosines. Navier, a former student of Fourier, offered a new expression for the elastic moment: It was proportional to an elastic constant, the cube of the plate's thickness (instead of the fourth power of Germain's), and also contained the product of the principal curvatures. This research in turn stimulated Cauchy to define how the stress of an elastic plate depended on the applied strain in terms of tensors while introducing a second elastic constant. Cauchy, and subsequently Kirchhoff, set the foundations of the present theory of elasticity.

These were Germain's final years. She fought a losing battle against breast cancer, while continuing to write her thoughts over the sciences and the arts, "Real superiority is nothing more than the means of considering difficult problems from a point of view whence they become easy, where the spirit can embrace them and follow them without effort." Germain did not live long enough to ripen the fruits of Gauss's request to the University of Göttingen to award her an honorary doctorate.

CRISTINA P. TANZI

FOR FURTHER READING: A.D. Dalmédico, "Sophie Germain," Scientific American Dec. (1991) p. 117; A.D. Dalmédico, "Mécanique et théorie des surfaces: les

Need Nanomechanical and Nanotribological Testing Services?

\section{Nanomechanics Research Laboratory}

\section{Nanoscale Mechanical and Tribological Characterization}

- Nanoindentation: hardness, modulus, fracture toughness

- Nanoscratch: critical load, delamination, interfacial adhesion

- Nanotribological test: lateral force, friction coefficient, wear, and lubrication effect

\section{Product Evaluation and Failure Analysis}

- Nanomechanical and tribological evaluation

- Failure mechanism analysis

- Root cause identification

- Product design improvement suggestion

HYSITRON, Inc

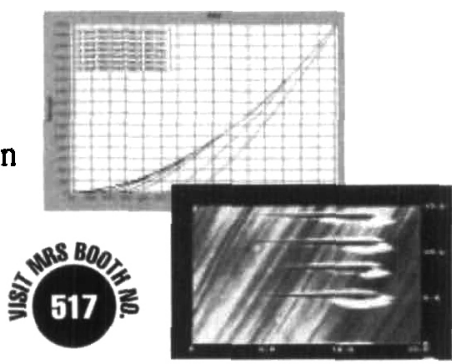

5251 W. $73^{\text {tid }}$ St.. Minneapolis, MN 55439. USA. Tel: (612) 835-6366 E-mail: test@hysitron.com

Circle No. 18 on Reader Service Card

travaux de Sophie Germain," Historia Math. 14 (4) (1987) p. 347; L.L. Bucciarelli and N. Dworsky, Sophie Germain: An Essay in the History of the Theory of Elasticity (D. Reidel, Dordrecht, 1980); S. Germain, Recherches sur la théorie des surfaces élastiques, par Sophie Germain (Mme. V. Courcier, Paris, 1821); H. Stupuy, "Notice sur la vie et les ouvres de Sophie Germain," Oeuvres philosophique de Sophie Germain (Paul Ritti, Paris, 1879), pp. 1-92.

\section{Christine Mirzayan Internship Program of the National Academies \\ WASHINGTON, DC}

The Christine Mirzayan Internship Program of the National Academies is designed to engage graduate and postdoctoral science, engineering, and law students in science and technology policy and to familiarize them with the interactions between science, technology, and government.

For the year 2000, the internship program will commence in both January (for 12 weeks, January 18-April 7) and June (for 10 weeks, June 5-August 11).

To apply, candidates should submit the application and one letter of reference. See website: national-academies.org/ internship.

The deadline for receipt of materials is December 1, for the January 2000 program and March 1, for the June 2000 program.

Additional questions should be directed to: internship@nas.edu. 
The Diamond Makers Robert M. Hazen

"Utterly absorbing... Hazen makes the story profoundly exciting, conveying the scientific passion of the researchers...It's a gem."

-The Washington Post

Discover how to make a diamond. Spanning centuries of groundbreaking science, instances of bitter rivalry, cases of outright fraud and self-delusion, Hazen blends drama and science to reveal the extraordinary technological advances and devastating failures of the synthetic diamond industry. $1999258 \mathrm{pp}$

0-521-65474-2 Paperback \$15.95

\section{Principles of Quantum Mechanics}

As Applied to Chemistry and Chemical Physics

Donald D. Fitts

An ideal textbook for beginning graduate students in materials science, this volume presents the basic principles of quantum mechanics using modern mathematical techniques and theoretical concepts, such as hermitian operators, Hilbert space, Dirac notation, and ladder operators. Throughout, basic theory is clearly illustrated and applied to the harmonic oscillator, angular momentum, the hydrogen atom, the variation method, perturbation theory, and nuclear motion.

$1999362 \mathrm{pp}$

0-521-65124-7 Hardback \$74.95

0-521-65841-1 Paperback \$39.95

\section{Polymers at Surfaces and Interfaces} Richard A. L. Jones and Randal W. Richards

Suitable for advanced undergraduates, graduate students, and researchers in materials science, this volume introduces statistical mechanics models of polymer behavior near interfaces, emphasiz ing theory that is applicable to experimental situations. Topics covered include the nature and properties of the surface of a polymer melt, the structure of interfaces among different polymers and between polymers and nonpolymers, the molecular basis of adhesion and the properties of polymers at liquid surfaces. Emphasis is placed on the underlying physical principles. $1999388 \mathrm{pp}$.

0-521-47440-X Hardback $\$ 90.00$

0-521-47965-7 Paperback \$39.95

\section{Vertical-Cavity Surface-Emitting Lasers}

Design, Fabrication, Characterization, and Applications

Carl Wilmsen, Henryk Temkin, and

Larry A. Coldren, Editors

Written by high-profile researchers in the field, this volume provides a complete introduction into the physics of VCSELs.

It also describes their wide range of potential application in

areas such as communications, printing, and optical switching.

$1999474 \mathrm{pp}$

0-521-59022-1 Hardback $\$ 100.00$

\section{Soft X-rays and Extreme Ultraviolet} Radiation

Principles and Applications

\section{David Attwood}

This comprehensive book describes the fundamental properties of soft x-rays and extreme ultraviolet (EUV) radiation and discusses their applications in a wide variety of fields, including EUV lithography for semiconductor chip manufacture and soft x-ray biomicroscopy. $1999488 \mathrm{pp}$.

0-521-65214-6 Hardback \$59.95

\section{Quantum Heterostructures}

Microelectronics and Optoelectronics

Vladimir V. Mitin, Viatcheslav A. Kochelap, and Michael A. Stroscio

This volume provides a detailed description of the key physical and engineering principles of quantum semiconductor heterostructures. Blending important concepts from physics, materials science, and electrical engineering, it also explains clearly the behavior and operating features of modern microelectronic and optoelectronic devices.

$1999662 \mathrm{pp}$

0-521-63177-7 Hardback $\$ 120.00$

0-521-63635-3 Paperback \$49.95

\section{Physics of Crystal Growth Alberto Pimpinelli and Jacques Villain}

This text discusses the physical principles of how and why crystals grow. It introduces the fundamental properties of crystal surfaces at equilibrium, and describes simple models and basic concepts of crystal growth including diffusion, thermal smoothing of a surface, and applications to semiconductors. It also covers more complex topics such as kinetic roughness, growth instabilities, and elastic effects, as well as the crucial contributions of crystal growth in electronics during this century. $1999400 \mathrm{pp}$

0-521-55198-6 Hardback $\$ 90.00$

0-521-55855-7 Paperback \$44.95

\section{Impact on Composite Structures Serge Abrate}

"The author, who developed his reputation in the field of impact of composite structures through his review papers, is one of the few individuals qualified to write a book of this nature. It represents excellent coverage of pertinent areas... nicely describes the overall problems related to structural impact.

\section{-AIAA Journal}

$1998301 \mathrm{pp}$

$0-521-47389-6$

Hardback \$64.95

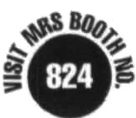

Available in bookstores or from

\section{CAMBRIDGE UNIVERSITY PRESS \\ 40 West 20th Street, New York, NY 10011-4211 Call toll-free 800-872-7423 Web site: www.cup.org \\ MasterCard/VISA accepted. Prices subject to change.}




\section{New from Springer}

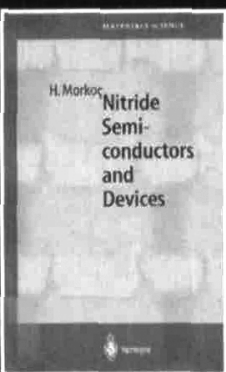

H. MORKOÇ, Virginia Commonwealth University, Richmond Nitride Semiconductors and Devices

This unique book is devoted to the important class of nitride semiconductors and devices. It succinctly treats structural, electrical, and optical properties of nitrides and the substrates on which they are deposited. It also covers band structures of nitrides, optical processes, deposition and metalization technologies, dopant incorporation, and analyses pn-junctions, light-emitting diodes, and blue lasers. Numerous tables and figures detailing properties and performance devices are included.

1999/475 PP., 271 ILLUS. (7 IN COLOR), 23 TABLES/HARDCOVER/\$116.00 ISBN 3-540-64038-X

SPRINGER SERIES IN MATERIALS SCIENCE. VOL. 32

A. GONIS, Lawnence Livermone Laboratory, CA, and W.H. BUTLER, Oak Ridge National Laboratory, IN

\section{Multiple Scattering in Solids}

Describes general techniques for solving linear partial differential equations by dividing space into regions to which the equations are independently applied and then assembling a global solution from the partial ones. It begins with an intuitive approach to scattering theory and then turns to partial waves and a formal development of multiple scattering theory. The authors also present a variational derivation of the formalism.

2000/APPROX. 350 PP., 44 ILUUS./HARDCOVER \$59.95/1SBN 0.387.98353-X

GRADUATE TEXTS IN CONTEMPORARY PHYSICS

R.E. HUMMEL, University of Florida, Gainesville Understanding Materials Science Mistory, Properties, Applleations

"Has succeeded admirably in nendering intrinsically complicated topics, such as polymerization. palatable and digestible. As a first-level introduction to materials science I recommend it unresenvedly."

- MRs BULLTIN

This introduction to materials science examines not oniry the physical and engineering properties of materials, but also their history, development. and uses. Exercises conclude chapters. Complimentury examination copies available to qualified instructors. 1998/407 PP., 326 ILLUS.(35 COLOR) HARDCOVER/\$59.95/ISBN 0.387-98303-1

J. DURAN, University of Paris $V$, France, and A. REISINGER, Lexington, MA

Sands, Powders, and Grains

\section{An introduction to the Physice} of Cranular Materials

This book covers the basic properties of flow, friction, and fluidization of uniform granular materials; discusses mixing and segregation of heterogeneous materials (the famous "brazil-nut problem"); and concludes with numerical models. 2000/APPROX. 315 PP., 212 ILLUS./HARDCOVER \$59.95/ISEN 0-387-98656-1 PARTIALY ORDERED SYSTEMS

\section{F. CARDARBLLI, Boucberville, Que., Canada}

\section{Materials Handbook}

\section{A Concise Desktop Reference}

This truly unique and practical book provides easy and rapid access to the accurate physical and chemical properties of most classes of materials. These classes are: metals and alloys, semiconductors, industrial ceramics and glasses, polymers and elastomers, minerals and rocks, timbers and woods, and building materials. Particular emphasis is placed on the properties of common industrial materials in each class. Detailed appendices and an extensive bibliography complete this guide. 2000/APPROX. 510 PP./HARDCOVER/\$116.00 ISBN 1-85233-168-2

T. SAITO, National Research Institute for Metals, Tsukuba-sbi, Japan (Ed.)

\section{Computational Materials Design}

This book outlines cutting-edge theories and techniques for computational materials design. It examines the effectiveness of the computational approach for understanding not only materials phenomena but also materials design and development. The book is directed to students, materials scientists, and engineers who need a clear exposition of modern technologies for materials design. 1999/296 PP, 212 LIUUS, 43 TABIES HARDCOVER/\$99.00/1SBN 3-54064377.X SPRINAER SERIES IN MATERIALS SCIENCE, VOL. 34

K. OHNO, K. ESFARJANI, and Y. KAWAZOR, all, Toboku University, Sendai, Japan

\section{Computational Materials Science \\ From Ab initlo to Monte Carto Mothods}

Introduces new theoretical techniques in materials research. Case studies and examples are presented and all the necessary equations and graphs are included so that readers can fully understand the details. This book offers the materials scientist access to, and an understanding of, modern developments based on molecular dynamics and Monte Carlo simulation.

1999/325 PP., 77 ILUS./HARDCOVER/\$94.00 ISEN 3540639616

SPRINGER SERIES IN SOLLDSTATE SCIENCES VOL. 129

\section{R.A. STREET, Palo Alto, CA (Ed.) Amorphous Silticon Tochnolosy and Appllcations}

Presents a comprehensive description of the current technology and its future potential so that the reader can understand how the particular properties of amorphous silicon lead to unique applications. Topics covered include the design of the amorphous silicon transistor and sensor devices, the range of matrix-addressed arrays and other systems that can be fabricated, and the performance of the various application areas. 2000/APPROX. 400 PP., 260 IUUS., 30 TABLES HARDCOVER/\$99.00/ISBN 3-640657142 SPRINGER SERIES IN MATERIALS SCIENCE, VOL. 37

U. HARTMANN, University of Saarbrïcken Germany (Ed.)

\section{Magnetic Multilayers} and Giant

\section{Magnetoresistance}

\section{Fundementals and}

\section{Industrilel Appilcations}

2000/APPROX. 335 PP. 150 ILUS. 15 TABIES HARDCOVER/ $\$ 89.95 / 158 N$ 3-64065568-9 SPRIMGER SERIES IN SURFACE SCIENCES, VOL 37

S. SUGANO, Nagano, and N. KOJIMA, University of Tokyo, both, Japan (Eds.)

\section{Magneto-Optics}

2000/APPROX. 350 PP., 235 FES., 15 TABS. HARDCOVER/S62.00/ISBN 3-64065961.7

SPRINGER SERIES SOLDSTATE SCIENCES, VOL. 128

A. HUBERT, Universität Erlangen-Nïmberg, and R. SCHÄFER, IFW, Dresden, Germany Masnetic Domains The Anabyeis of Magnotic Milerostructures

1998/720 PP., 400 ILUUS. (4 COLOR)/HARDCOVER $\$ 119.00 / 15 B N$ 3-540-64108-

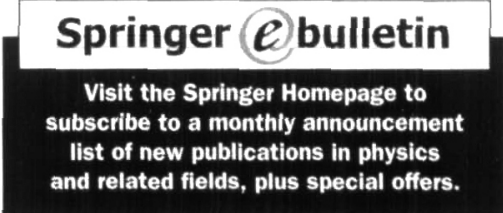

Physics at Its Best CALL Toll-Free 1-800-SPRINGER 8:30 AM - 5:30 PM: Please mention $\mathrm{S} 1313$ when ordering by phone. FAX 201-348-4505 FAX 201-348-4505. orders@springer.de WRilt to Springer-Verlag New York, Inc. Attn: K. Quinn, Dept. S1313, 175 Fifth Avenue. New York, NY 10010-7858. visi your local scientific bookstore or urge your librarian to order.

$12 / 99$

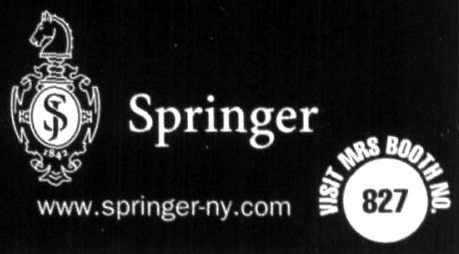


Find us at the MRS conference in Boston! Booth 1024. 15-30\% Conference Discount!

\section{Comprehensive RESOURCES} Academic Press

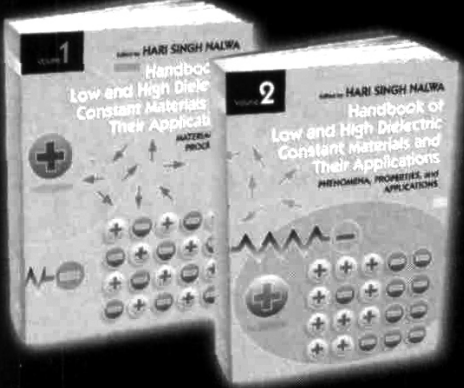

HANDBOOK OF LOW AND High Dielectric Constant Materials AND Their Applications Hari Singh Nalwa

Volume 1: Materials and Processing

Volume 2: Phenomena, Properties and Applications

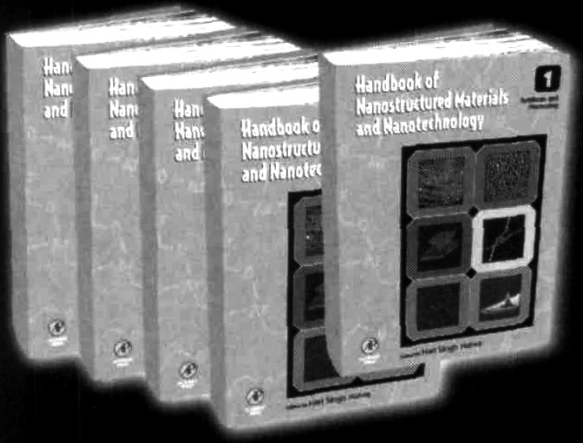

HANDBOOK OF NANOSTRUCTURED

Materials AND

NANOTECHNOLOGY

Hari Singh Nalwa

Foreword by Nobel Prize Laureate George Olah

Volume 1: Synthesis and Processing

Volume 2: Spectroscopy and Theory

Volume 3: Electrical Properties

Volume 4: Optical Properties

Volume 5: Organics, Polymers, and Biological Materials

October 1999, c. 3.608 pp., $\$ 1,500.00$

ISBN:0-12-513760-5

\section{Cracks and Fracture}

K. Bertram Broberg

March 1999, 752 pp., \$99.95/ISBN:0-12-134130-5 July 1999, 1,152 pp., \$895.00/1SBN:0-12-513905-5
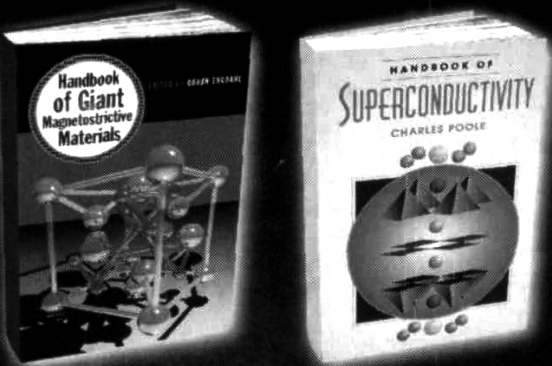

HANDBOOK OF GIANT

MAGNETOSTRICTIVE

\section{MATERIALS}

Goran Engdahl

October 1999 , c. 400 pp., $\$ 160.00$

ISBN:0-12-238640-X

\section{ELECTRODYNAMICS OF Materials $\gamma$}

Forces, Stresses and Energies in Solids and Fluids

Scipione Bobbio

September 1999, c. 384pp., $\$ 79.95$ ISBN:0-12-108260-1

\section{EXPERIMENTAL MeTHODS IN Polymer Science Modern Methods in Polymer Research and Technology \\ Toyoichi Tanaka \\ September 1999, c. 505 pp., $\$ 95.00$ ISBN:0-12-683265-X}

\section{HandBoOK OF}

SUPERCONDUCTIVITY

Charles Poole

October 1999 , c. 648 pp.. $\$ 95.00$ ISBN:0-12-561460-8

\section{Optical Materials}

Joseph H. Simmons

Kelly S. Potter

September 1999 , c. 372 pp., $\$ 79.95$

ISBN:0-12-644140-5

\section{Solid State Physics}

Giuseppe Pastori Parravicini Giuseppe Grosso

October 1999,768 pp., $\$ 79.95$

ISBN:0-12-304460-X
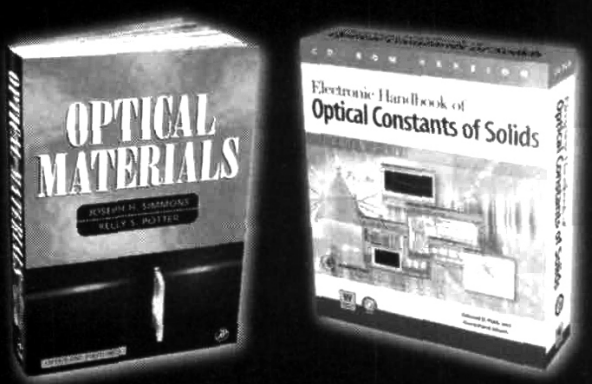

Handbook of Optical CONSTANTS OF SOLIDS

Edward D. Palik

Gorachand Ghosh

5 volume Casebound Set, 1997, 3440 pp., $\$ 850.00$ ISBN:0-12-544415-X

Electronic Version, July 1999, $\$ 1,800.00$ ISBN:0-12-544455-9

\section{LASER AbLation AND DESORPTION}

Experimental Methods in the Physical Sciences, Volume 30

John C. Miller

Richard F. Haglund

1998, 672 pp., \$95.00/ISBN:0-12-475975-0

\section{Gallium Nitride}

2 Volume Set

Jacques I. Pankove

Theodore D. Moustakas

Invaluable paperback reprint of Semiconductors and Semimetals Volumes 51 and 57 .

September 1999 , c. 1008 pp., $\$ 99.95$

ISBN:0-12-544055-3

\section{SEMICONDUCTORS AND SEMIMETALS}

VOLUME 62: INTERSUBBAND TRANSITIONS IN QUANTUM WELLS

October 1999 , c. 576 pp., $\$ 160.00$

ISBN:0-12-752171-2

VOLUME 63: CHEMICAL MECHANICAL POLISHING IN SILICON PROCESSING October 1999, c. $400 \mathrm{pp}$., $\$ 160.00$ (tentative) ISBN:0-12-752172-0

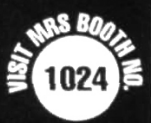

Order from your local bookseller or directly from

Academic Press

Order Fulfillment Dept. DM27098

6277 Sea Harbor Drive

Orlando, FL 32887
TEL: 1-800-321-5068 FAX: 1-800-874-6418 E-MAlL: ap@acad.com
Find us on the Web! www.academicoress.com

\section{(AP) ACADEMIC PRESS}

Prices in U.S. dollars and subject to change without notice. () 1999 by Academic Press. All Rights Reserved. KS/NA/PECS-02119 9/99 